\title{
Development of Two-Phase Flow Regime Specific Pressure Drop Models for Proton Exchange Membrane Fuel Cells
}

\section{Authors: Ryan Anderson, Erica Eggleton, \& Lifeng Zhang}

This is a postprint of an article that originally appeared in International Journal of Hydrogen Energy in January 2015.

http://www.journals.elsevier.com/international-journal-of-hydrogen-energy/

Anderson, Ryan, Erica Eggleton, and Lifeng Zhang. Development of two-phase flow regime specific pressure drop models for proton exchange membrane fuel cells. International Journal of Hydrogen Energy. January 2015. Pages 1173-1185.

https://dx.doi.org/10.1016/j.ijhydene.2014.11.032

Made available through Montana State University's ScholarWorks 


\title{
Development of Two-Phase Flow Regime Specific Pressure Drop Models for Proton Exchange Membrane Fuel Cells
}

\author{
Ryan Anderson ${ }^{\mathrm{a}, 1}$, Erica Eggleton ${ }^{\mathrm{a}}$, Lifeng Zhang ${ }^{\mathrm{b}, 1}$ \\ ${ }^{a}$ Department of Chemical and Biological Engineering, Montana State University, Bozeman, MT \\ 59718 \\ bDepartment of Chemical and Biological Engineering, University of Saskatchewan, Saskatoon, \\ SK, Canada, S7N 5A9
}

\begin{abstract}
Water is an inevitable byproduct in proton exchange membrane fuel cells that can lead to complex two-phase flow throughout the cell's components, including the flow field channels utilized for gas delivery. A modified Lockhart-Martinelli (LM) approach based on unique water introduction through the gas diffusion layer is used here to predict the gas-liquid pressure drop in these channels by modifying the Chisholm parameter $C$. This paper exclusively uses experimental data of two-phase flow multipliers from four sources in the literature, all of which are obtained from active fuel cell operation. $C$ does not appear to change strongly as a function of temperature, relative humidity, or air stoichiometry, but does vary significantly with the current density. This is especially true at low current densities $\left(<500 \mathrm{~mA} \mathrm{~cm}^{-2}\right)$. To capture this behavior, $C$ is defined as a flow regime dependent parameter based on a flow regime map from the active fuel cell data. In addition to the traditionally used slug, film, and single-phase regimes, an 'accumulating' flow regime is proposed to capture the behavior of $C$ and two-phase flow multipliers at low current densities. The proposed accumulating flow regime is consistent with visual observation reported in the literature. In addition, the developed LM approach can be employed to optimize fuel cell flow field design and operation.
\end{abstract}

Keywords: water management, PEM fuel cells, flow regimes, two-phase flow, pressure drop, Lockhart-Martinelli approach

${ }^{1}$ Corresponding authors: ryan.anderson@coe.montana.edu; Lifeng.zhang@usask.ca

Phone: 1-406-994-5701 Fax: 1-406-994-5308 


\section{INTRODUCTION}

Proton exchange membrane fuel cells (PEMFCs) continue to be of interest in the emerging portfolio of clean energy technologies. Key advantages include high power density, no $\mathrm{CO}_{2}$ or $\mathrm{NO}_{\mathrm{x}}$ emissions at the point of use, and continuous power production with reactant supply. The overall reaction for the hydrogen fuel cell is highlighted here to emphasize the inevitable production of water:

$$
\mathrm{H}_{2}+\frac{1}{2} \mathrm{O}_{2} \rightarrow \mathrm{H}_{2} \mathrm{O} \quad \mathrm{E}^{\mathrm{o}}=1.23 \mathrm{~V}
$$

The presence of liquid water and its effect on pressure drop in the flow channels is the focus of this paper based on existing literature data from active fuel cells [1-4]. This extends the work in [5] that considered this data in terms of fuel cell operating conditions.

Managing the product water remains a critical issue in PEM fuel cell performance [6]: insufficient water dehydrates the membrane, which lowers proton conductivity, and excessive water causes 'flooding' in the fuel cell. Both flooding and drying reduce cell performance [7,8]. Water accumulation in the flow channel can not only decrease the voltage but can also lead to a less stable voltage signal $[9,10]$. Liquid water in the channels also increases the pressure drop in the flow field channel [11-13], which is a parasitic power loss of the system with increased energy consumed when supplying the reactants [14]. Much work has been done to resolve these issues by varying the operating conditions (e.g. gas flow rate, relative humidity, temperature, pressure etc.) and changing the properties of components (e.g. flow field design, gas diffusion layer (GDL) design) [15,16].

Liquid water from the reaction transports through the diffusion media (GDLs) into the flow field channel. This injection mechanism is perpendicular to the direction of gas flow. Though water is electrochemically produced on the cathode side, it should be noted that a complex water balance exists between anode and cathode sides [8]. Flooding can occur throughout the fuel cells layers, shown schematically in Fig. 1a and further explained in [67-8]. In order to observe the gas-liquid flow in the flow field channels, transparent fuel cells are used [16] such as the one in Fig. $1 \mathrm{~b}$ that was used to collect data in [3,4]. While other methods exist [17], such as nuclear magnetic resonance imaging [18], neutron radiography [19], and X-ray imaging [20], optical visualization remains popular due to availability, cost, and material constraints. 

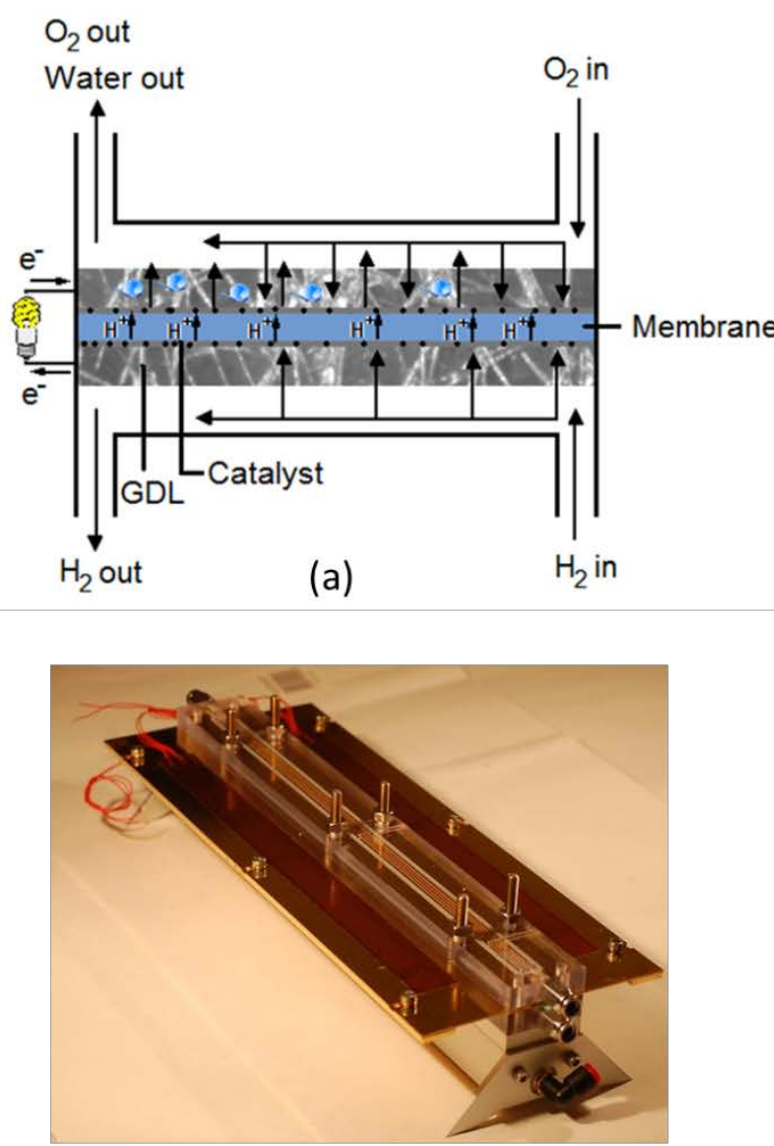

(b)

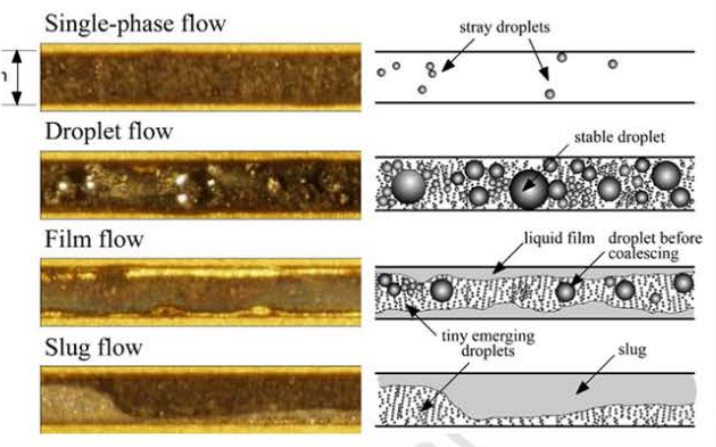

(i)

(ii)

(ii)

(iv)

(c)

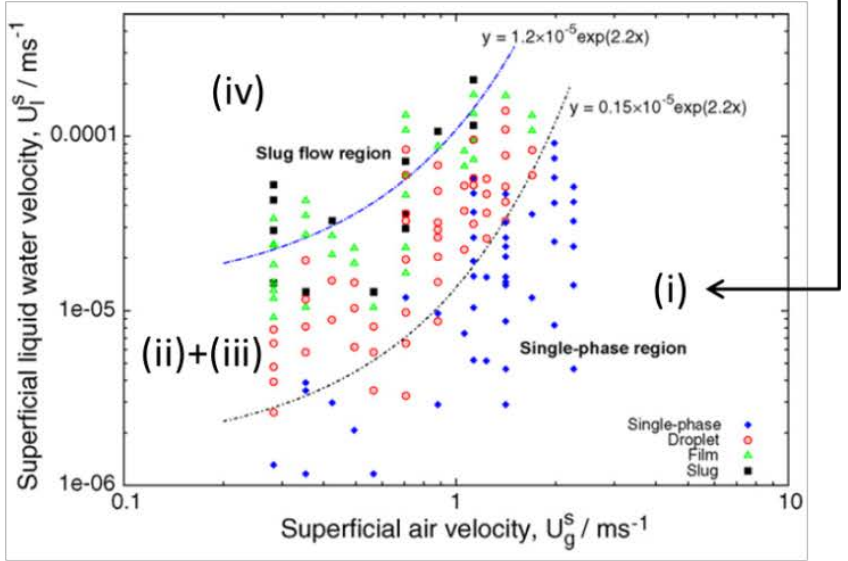

(d)

Fig. 1. a) Typical fuel cell architecture with gas channels for air or oxygen (cathode) and hydrogen (anode), respectively. The membrane, catalysts, and porous diffusion media (GDLs) are also shown (not to scale) b) A visualization fuel cell using metallic flow field channels and an optically transparent top plate c) The same flow field channel under various conditions showing the main flow patterns in an active fuel cell [1; Modified and printed with permission from Elsevier] d) A flow regime map based on gas and liquid velocities showing slug, droplet/film, and a single-phase region [1; Modified and printed with permission from Elsevier]

The flow patterns in an operating PEM fuel cell were first identified by Hussaini and Wang [1] as shown in Fig. 1c. The flow regime map they created is shown in Fig. 1d. The main flow patterns identified in the map are film and droplets in between slug flow and 'single-phase' flow. As noted in [5], this map reasonably approximates the flow regime map generated by See et al. [2], also obtained in an operating fuel cell. As explained by Kandlikar et al. [21], slug flow is large liquid plugs with large gas pockets in between, film flow is liquid on the channel walls with significant gas pockets (and in rectangular geometries may only cover one channel), and mist flow is the liquid as small droplets in the gas flow. In this paper, film and droplet flows are 
considered together to be consistent with the map in Fig. 1c as are mist and single-phase flow since both lead to pressure drops close to the single-phase gas flow. In addition to physical observation, these regimes are further characterized by distinct pressure drop fluctuations and two-phase flow multipliers (ratio of two-phase pressure drop to single-phase pressure drop) [21]. In addition to visual observation, recent progress has been made in an ex-situ (nonelectrochemically active) setup to use image processing to determine the flow regime under conditions relevant to PEM fuel cells [22].

Much of the work in multiphase PEMFC modeling uses computational fluid dynamics (CFD), which provides detailed analysis to understand the behavior of liquid water in the flow field channels [23-29]. While providing interesting and useful information such as droplet dynamics and pressure drop, these models are usually computationally intensive and are limited in their ability to couple the physics in the individual fuel cell layers over different spatial and temporal scales. Furthermore, a review on slug flow hydrodynamics in minichannels concluded that gaps in numerical understanding exist for gas-liquid flows in terms of flow pattern prediction, slug formation, and film thickness [30].

CFD tools are unnecessary if the goal is to approximate the multiphase pressure drop. A commonly used approach to determine the two-phase pressure drop in gas-liquid systems was developed by Lockhart and Martinelli (LM) [31]. The LM approach from Chisholm [32] for laminar gas and laminar liquid flows (generally applicable to the typical PEMFC system) says the two-phase pressure drop can be related to the single-phase pressure drop by:

$$
\varphi^{2}=1+\mathrm{C} \chi+\chi^{2}=\frac{\Delta \mathrm{P}_{\mathrm{gl}}}{\Delta \mathrm{P}_{\mathrm{g}}}
$$

where $\chi^{2}$ can be simplified (laminar flows for both gas and liquid) to:

$$
\chi^{2}=\frac{\Delta P_{l}}{\Delta P_{g}}=\frac{u_{L} \mu_{L}}{u_{g} \mu_{g}}
$$

Eq. 2 is the two-phase pressure drop multiplier $\left(\varphi^{2}\right)$. The standard LM approach assumes liquid water and air are mixed and flowing uniformly in the channel at the inlet. However, water in the operating PEM fuel cell dominantly enters the flow field channel from the GDL perpendicular to the air flow direction. Thus, Zhang et al. [33] modified this approach to be more relevant to fuel cells, which is detailed in Section 2. The modified approach is based on ex-situ experiments with limited pressure data from active fuel cells available at that time. As several research groups have 
been reporting data for two-phase pressure drop and two-phase pressure drop multiplier (as in Eq. 2), it is timely to evaluate how well this approach works with active fuel cells.

This paper utilizes the modified LM approach from Zhang et al. [33] to study all recent experimental data on two-phase flow pressure drop in operating PEM fuel cells. To the best of our knowledge, no attempt has been made to interpret active fuel cell pressure drop data from this perspective. A brief summation of the model development is provided along with a description of key fuel cell parameters. From the updated equations for the LM approach in [33], the value of the parameter $C$ is obtained over a range of values from available pressure drop data. $C$ is explored as a flow regime dependent parameter with a unique expression as a function of the current density for each regime. Based on the literature and this analysis, a new flow regime, the 'accumulating' regime, is defined and added to the flow regime map developed by Hussaini and Wang [1]. The sensitivity of the expressions and a guide for fuel cell designers is provided.

\section{NOMENCLATURE}

$\begin{array}{ll}\text { A } & \text { coefficient from [13] } \\ \text { b } & \text { coefficient from [13] } \\ C & \text { Chisholm parameter } \\ \mathrm{C}^{*} & \text { constant } \\ \mathrm{D}_{\mathrm{H}} & \text { hydraulic diameter (m) } \\ \mathrm{F} & \text { Faraday’s constant }\left(\mathrm{C} \mathrm{mol}^{-1}\right) \\ \mathrm{GDL} & \text { gas diffusion layer } \\ \mathrm{I} & \text { current }(\mathrm{A}) \\ \mathrm{i} & \text { current density (mA cm } \\ \dot{\mathrm{N}} & \left.\text { molar flow rate }(\mathrm{mol} \mathrm{s})^{-1}\right) \\ \Delta \mathrm{P} & \text { pressure drop (Pa) } \\ \mathrm{u} & \left.\text { gas velocity (m s }{ }^{-1}\right) \\ \mathrm{Y} & \text { constant } \\ \mathrm{Z} & \text { constant } \\ \varphi^{2} & \text { two-phase flow multiplier } \\ \chi & \text { Martinelli parameter } \\ \mu & \text { viscosity (Pa s) } \\ \lambda_{\mathrm{i}} & \text { gas stoichiometry of gas i }\end{array}$




\section{MODIFIED LM APPROACH}

Considering the unique water transport in fuel cells, two water injection modes have been studied for their relevance to PEMFCs: uniform water injection and non-uniform water injection [33]. Both cases consider that the liquid water velocity varies as a function of distance $x$ along the channel, which is consistent with how water is injected into the gas flow channels of an operating PEM fuel cell. A schematic and development of the subsequent equations for these approaches is in $[5,33]$. Compared to the uniform injection mode, the non-uniform injection case is preferred as it assumes that the liquid water injection follows Darcy's law: the lowest pressure in the gas flow channel is at the exit, and thus the largest driving force for liquid water injection is at this point. There is a linear profile of injected water, leading to a parabolic expression for the liquid water velocity in the flow field channel. The resulting expression for the non-uniform LM approach is given in Eq. 4.

$\varphi_{g}^{2}=1+\left(\frac{1}{2}\right) C \chi+\left(\frac{1}{3}\right) \chi^{2}$

Specific to PEM fuel cells, the value for $\chi^{2}$ is fixed at a given set of experimental conditions regardless of the current density. This results from Faraday's Law where the required molar flow rates of hydrogen, oxygen (or air), and water $\left[\mathrm{mol} \mathrm{s}^{-1}\right]$ for the electrochemical reaction at standard conditions are given as:

$$
\dot{\mathrm{N}}_{\mathrm{H}_{2}}=\frac{\mathrm{I}}{2 \mathrm{~F}} \quad \dot{\mathrm{N}}_{\mathrm{O}_{2}}=\frac{\mathrm{I}}{4 \mathrm{~F}} \quad \dot{\mathrm{N}}_{\mathrm{H}_{2} \mathrm{O}}=\frac{\mathrm{I}}{2 \mathrm{~F}}
$$

I is the current $[\mathrm{A}]$ and $\mathrm{F}$ is the Faraday Constant $\left[9.6485 \times 10^{4} \mathrm{C} \mathrm{mol}^{-1}\right]$. The ratio between fluxes (and thus velocities in Eq. 3) is fixed at a given current, leading to a fixed value of $\chi^{2}$. However, the reactants are typically supplied in excess of these required amounts, and the ratio of supplied gas to needed gas is termed the 'stoichiometry' $\left(\lambda_{\mathrm{i}}\right)$.

In this work, analysis of two-phase pressure data focuses on air and water in the cathode flow field channel. To calculate the parameter $\chi^{2}$ for each data set, the viscosity of air was evaluated at the specific temperature and relative humidity conditions [34], and the viscosity of liquid water also varied as a function of temperature [35] (evaluated at $0.1 \mathrm{MPa}$ ). The velocity of the water in these calculations is the volumetric flow rate converted from Eq. 5 (the total flux of water produced electrochemically) divided by the cross-sectional area of the channel. The air velocity was corrected for the operating temperature and pressure via the ideal gas law. Thus, this 
approach utilizes $\chi^{2}$ to compare data sets of varying active areas, flow-field designs (e.g. type and dimensions), and operating conditions (e.g. temperature, pressure, gas relative humidity).

\section{DESCRIPTION OF AVAILABLE EXPERIMENTAL DATA}

Data was collected from multiple research groups, and key conditions are presented in Table 1. To study the Chisholm parameter $C$, the two-phase flow multiplier data was collected for each group. Then, $\chi^{2}$ was calculated at each condition. $C$ was then calculated from Eq. 4.

Hussaini and Wang [1] developed a transparent PEM fuel cell to allow for direct visualization of liquid water with the cathode air. The conditions for the two-phase flow multiplier of See [2] allowed for a direct comparison of GDL data. Anderson et al. [3] also provided two-phase flow multiplier data for a visualization fuel cell with a parallel channels. Additional data in a non-transparent, serpentine flow field channel fuel cell (the TP-50) was collected by Anderson [4].

Table 1. Conditions for the data collected here from [1-4] highlighting the operating conditions (temperature, pressure, relative humidity, gas stoichiometry), fuel cell design (active area, flow channel design), and cathode gas diffusion layer

\begin{tabular}{|c|c|c|c|c|}
\hline Variable & $\begin{array}{l}\text { Hussaini and } \\
\text { Wang [1] }\end{array}$ & See and Kandlikar [2] & Anderson et al. [3] & $\begin{array}{l}\text { Anderson [4]: } \\
\text { serpentine flow field }\end{array}$ \\
\hline $\begin{array}{l}\text { Relative humidity } \\
\text { of air (\%) }\end{array}$ & $25,42,66$ & 0,100 & 100 & 100 \\
\hline Air stoichiometry & $2,2.5,3,3.5,4$ & $2.5,5,8$ & $1.5,2,3,4$ & 2 \\
\hline $\begin{array}{l}\text { Current density } \\
\left(\mathrm{mA} \mathrm{cm}^{-2}\right)\end{array}$ & $200,500,800$ & $\begin{array}{l}\text { 50, 100, 150, 200, } \\
250 \ldots 400,500,600\end{array}$ & $\begin{array}{l}50,100,200,400 \\
\ldots 1000\end{array}$ & $\begin{array}{l}50,100,200,400 \\
\ldots 2000\end{array}$ \\
\hline Active area $\left(\mathrm{cm}^{2}\right)$ & 14 & 50 & 35.7 & 49 \\
\hline $\mathrm{T}_{\text {inlet }}\left({ }^{\circ} \mathrm{C}\right)$ & 80 & 40 & $30,50,75,90$ & 75 \\
\hline $\mathrm{P}_{\text {inlet }}\left(\mathrm{kPa}_{\mathrm{g}}\right)$ & 101.3 & 101.3 & 206.8 & 206.8 \\
\hline Flow-field & $\begin{array}{l}7 \text { parallel } \\
\text { channels }\end{array}$ & 22 parallel channels & 4 parallel channels & $\begin{array}{l}\text { Single-serpentine, } 27 \\
\text { bends, Trapezoidal }\end{array}$ \\
\hline $\begin{array}{l}\text { Channel } \\
\text { dimensions } \\
\text { (lx w x d ; mm) }\end{array}$ & $100 \times 1 \times 0.5$ & $273 \times 0.7 \times 0.4$ & $300 \times 1 \times 1$ & $1.56 \mathrm{~mm}^{2}$ \\
\hline Cathode GDLs & $\begin{array}{l}\text { Toray carbon } \\
\text { paper }\end{array}$ & $\begin{array}{l}\text { MRC-105, Freudenberg } \\
\text { H2315 }\end{array}$ & SGL 25BC & SGL 25BC \\
\hline
\end{tabular}

The See data [2] for MRC-105 with $\mathrm{RH}=0 \%$ was not included due to general disagreement with other trends; the two-phase flow multiplier at $0 \%$ relative humidity (lower water content) was higher than at $100 \%$ relative humidity, and the value for $C$ did not follow the general trend of lowering $C$ with increased current density. One addition multiplier value from [2] was 
removed (Freudenberg H2315, cathode stoichiometry of $5,50 \mathrm{~mA} \mathrm{~cm}^{-2}, \varphi^{2}=5.75$ ) as it is an outlier with 95\% confidence. Also, only the descending approach results from Anderson [3,4] are considered to be more consistent with long-term operation/water production. Overall, 172 data points were included in the analysis.

\section{TRADITIONAL APPLICATIONS OF THE LM APPROACH IN PEM FUEL CELLS}

The two-phase flow multiplier results available from the literature are shown in Fig. 2. As stated earlier, $\chi^{2}$ is fixed at a given set of experimental conditions by Faraday's Law. However, as can be seen in Fig. 2, there is a large spread in the two-phase flow multiplier at fixed $\chi^{2}$. Furthermore, for typical values of $C$ for laminar flow regimes $(C \leq 5)$, the LM approach underpredicts the two-phase flow multipliers for most data sets regardless of which water injection mechanism is considered [33].

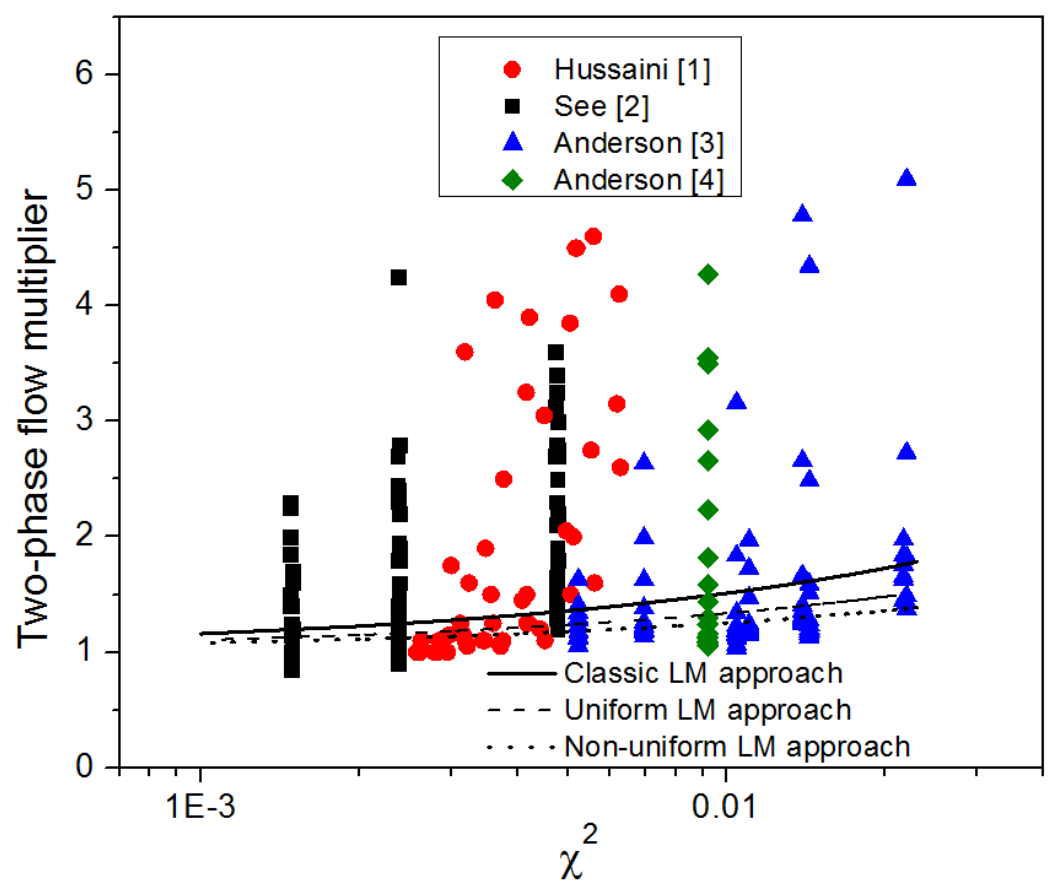

Fig. 2. All two-phase flow multiplier data for all conditions as a function of $\chi^{2}$ with $C=5$ based on the three water injection approaches studied by Zhang et al. [33]

Clearly, these expressions are not able to capture the multiphase dynamics occurring in the flow field channels in the operating fuel cell; namely, $\chi^{2}$ is unable to 'normalize' the data sets. In our recent work [5], $C$ was further examined in terms of gas stoichiometry, GDL, relative humidity $(\mathrm{RH})$, and whether the flow rates were changed in an ascending or a descending order. In each 
case, the $C$ parameter could not be explained by these common fuel cell variables. It was found that lower stoichiometries and higher relative humidities tended towards higher values of $C$, though there were exceptions throughout the analysis [5].

Nevertheless, it was clear in each case that the low current densities had higher values of $C$. These results are shown in Fig. 3a. It appears that the two-phase flow multiplier in all data sets tends to be quite high at lower current density (approximately $<500 \mathrm{~mA} \mathrm{~cm}^{-2}$ ). We hypothesize that high two-phase flow multipliers are associated with water accumulation at lower current densities where air flow rates are not sufficient to remove product water.
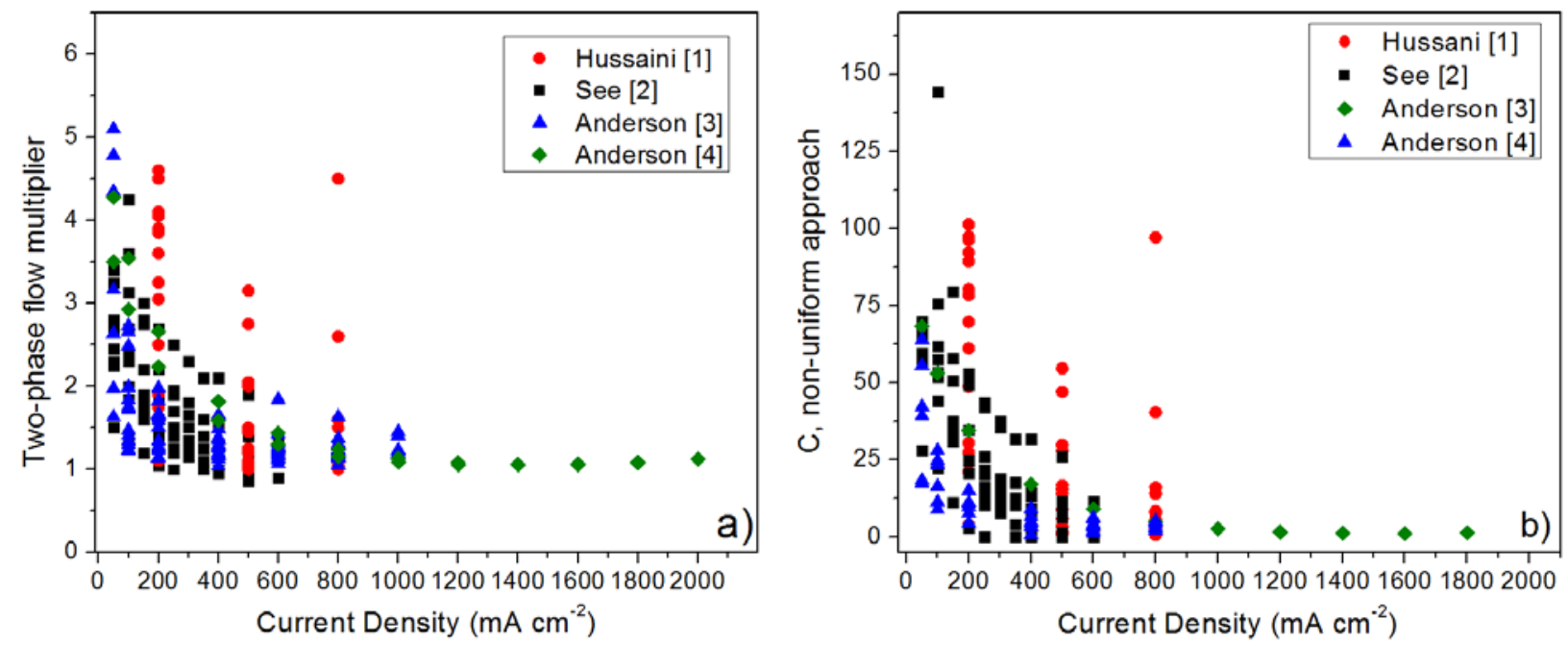

Fig. 3. a) Two-phase flow multiplier as a funciton of current density for the active fuel cell data in the literature [1-4] b) Calculated value of $C$ for the data in (a) based on Eq. 4 and the $\chi^{2}$ values in Fig. 2

The $C$ value based on the non-uniform approach (Eq. 4) vs. current density is shown in Fig. 3b. Again, no clear trend is noted for how $C$ varies with current density except that low current densities tend towards much higher values of $C$. Also, $C$ here is much greater than a typical value of 5 used in the LM approach for laminar-laminar (liquid-gas) flows, such as those typically experienced in PEM fuel cells. Chisholm suggested $C=5,10,12$, and 20 for laminar-laminar, turbulent-laminar, laminar-turbulent, and turbulent-turbulent flows, respectively [32,36]. Table 2 shows how much of the current data being analyzed is inconsistent with these traditional values of $C$. Much of the data (73\%) has a value of $C$ greater than the typical laminar-laminar value of 5. Further, $43 \%$ of the data is above the criterion for turbulent-turbulent flows $(C \geq 20)$, which is not typical in PEM fuel cell operation. There is therefore a need to update the LM approach for broad applicability to active PEM fuel cells. 
Table 2. Emphasizing how many data points from across the literature have $C$ values substantially higher than expected based on various criteria for $C$.

\begin{tabular}{ccc} 
Criteria & Count & \% of Total Data \\
\hline$C \geq 5$ & 125 & $73 \%$ \\
$C \geq 10$ & 104 & $60 \%$ \\
$C \geq 12$ & 95 & $55 \%$ \\
$C \geq 20$ & 74 & $43 \%$
\end{tabular}

\subsection{Previous literature approaches to $C$ applied to active PEM fuel cell data}

A few attempts were made to modify $C$ to predict two-phase pressure drop using the standard LM approach. $C$ has also been studied in systems specific to minichannels. For instance, English and Kandlikar [37] presented the following for diameters based on a $1 \mathrm{~mm}$ square channel:

$$
C_{E-K}=5 *\left(1-\exp \left[-319 D_{H}\right]\right)
$$

Table 3 shows the value of $C_{E-K}$ for the groups studied here. It is interesting to note the magnitude of the standard deviation for the data sets, highlighting the spread of the data and further necessitating the need for a more refined approach to calculating $C$ in order to use the LM approach. While a valid approximation to microchannels, these $C_{E-K}$ values are lower than the high values of $C$ needed at low current densities. Even based on the standard LM approach [33], the experimental values of $C$ are well beyond this calculation.

Table 3. Chisholm parameter from English and Kandlikar [37] ( $\left.C_{E-K}\right)$ compared to minimum, maximum, and average $C$ for all the data considered here (non-uniform approach from Eq. 4)

\begin{tabular}{l|cccc}
\hline Data Source & $\boldsymbol{C}_{\mathbf{E}-\boldsymbol{K}}$ & $\boldsymbol{C}_{\min }$ & $\boldsymbol{C}_{\max }$ & $\boldsymbol{C}_{\boldsymbol{a v g}}$ \\
\hline Hussaini and Wang [1] & 0.96 & 0.60 & 101.3 & $30+/-34$ \\
See and Kandlikar [2] & 0.75 & 0.0 & 144.3 & $30+/-26$ \\
Anderson [3] & 1.37 & 0.71 & 64.0 & $14+/-16$ \\
Anderson [4] & 1.62 & 1.19 & 68.3 & $18+/-24$
\end{tabular}

An updated model from Grimm et al. [13] also proposed an updated correlation based on exsitu fuel cell results that utilized water injection through a GDL. Their expression is given by:

$$
C_{\text {Grimm }}=A\left(\frac{1-x}{x}\right)^{b}
$$

where:

$$
A=0.0856 * u_{L}^{-1.202}
$$




$$
b=0.004 * u_{L}^{-0.526}
$$

The term $(1-x) / x$ is the ratio of air to liquid quality. This has been applied to all of the active fuel cell data in this paper [1-4] with the results in Fig. 4. In each case, the two-phase flow multiplier calculated by the method of Grimm et al. [13] over-predicts the values compared to the experimental data.
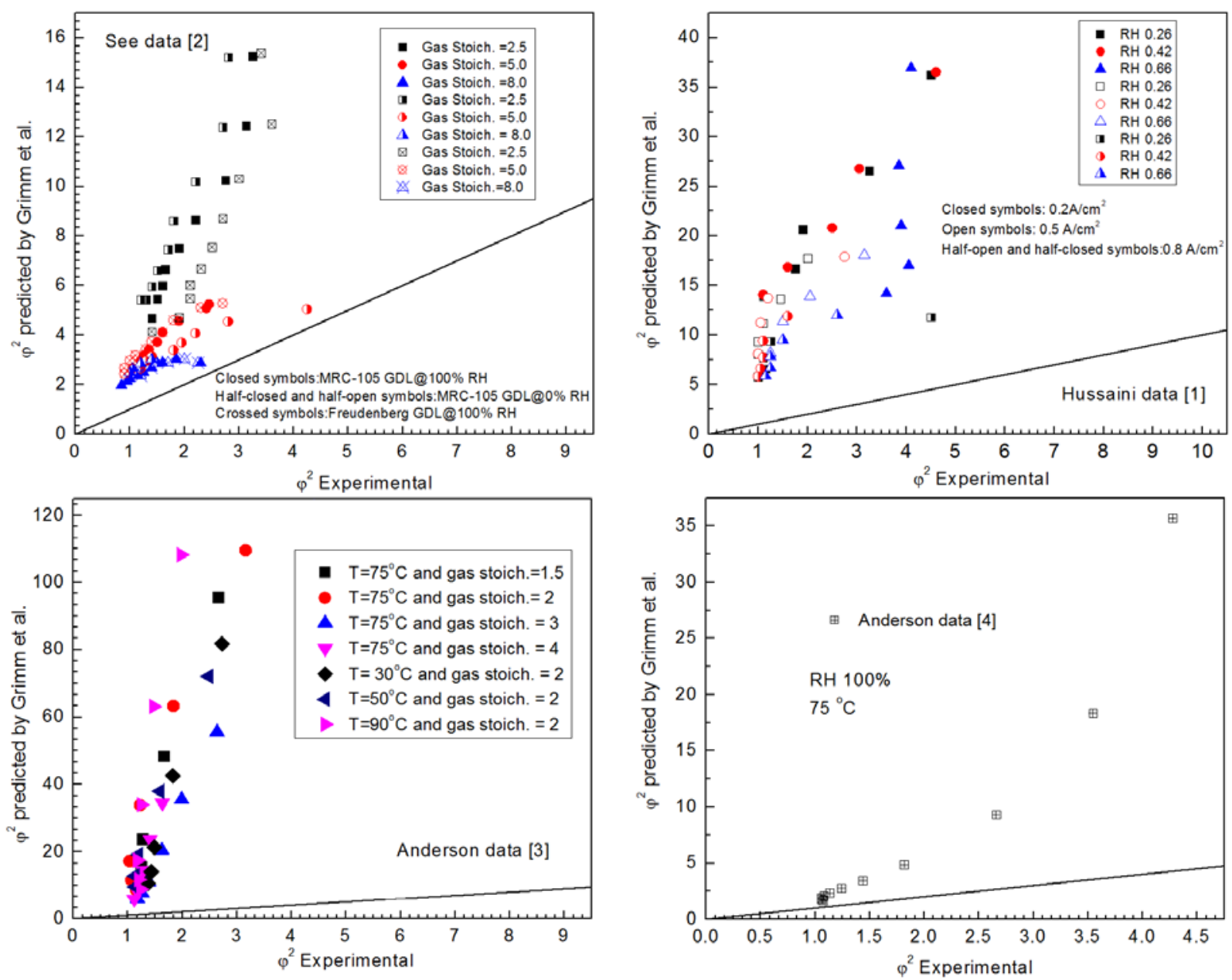

Fig. 4. Two-phase flow multiplier calculated from $C_{\text {Grimm }}$ vs. the experimentally measured two-phase flow multipler in each group [1-4]. The solid line has a slope of 1 to indicate where the experiment and model agree.

However, as will be discussed in the following section, this is likely due to the ex-situ flow pattern maps where much of the data here would be considered slug flow (and hence a higher prediction for $C$ ) even though the in-situ flow maps indicate 'single-phase' or mist flow. 


\subsection{Previous flow regime maps from literature}

This approach for active fuel cells is to consider $C$ as a flow regime dependent parameter as it applies to operating PEM fuel cells. This method has been done with non-active fuel cell data [13] but not with electrochemically active fuel cell data. Collecting from four groups has the benefit of broader applicability as each group has used different fuel cells, materials, and operating conditions. Here, the flow regime map generated by Hussaini and Wang [1] (Fig. 1b) is used to define the boundaries of slug, film/droplet, and 'single' phase flow. This map was shown to qualitatively agree with the map from See [2] with similar superficial gas and liquid velocities for equivalent flow patterns, even though the two groups studied different conditions (differing temperatures, relative humidities, GDLs etc.) [5]. The Hussaini and Wang [1] flow regimes applied to the data in this paper are in Fig. 5a. Slug flow is noted at low gas velocities and high liquid velocities with 'single’ phase flow at low liquid velocities and high gas velocities.
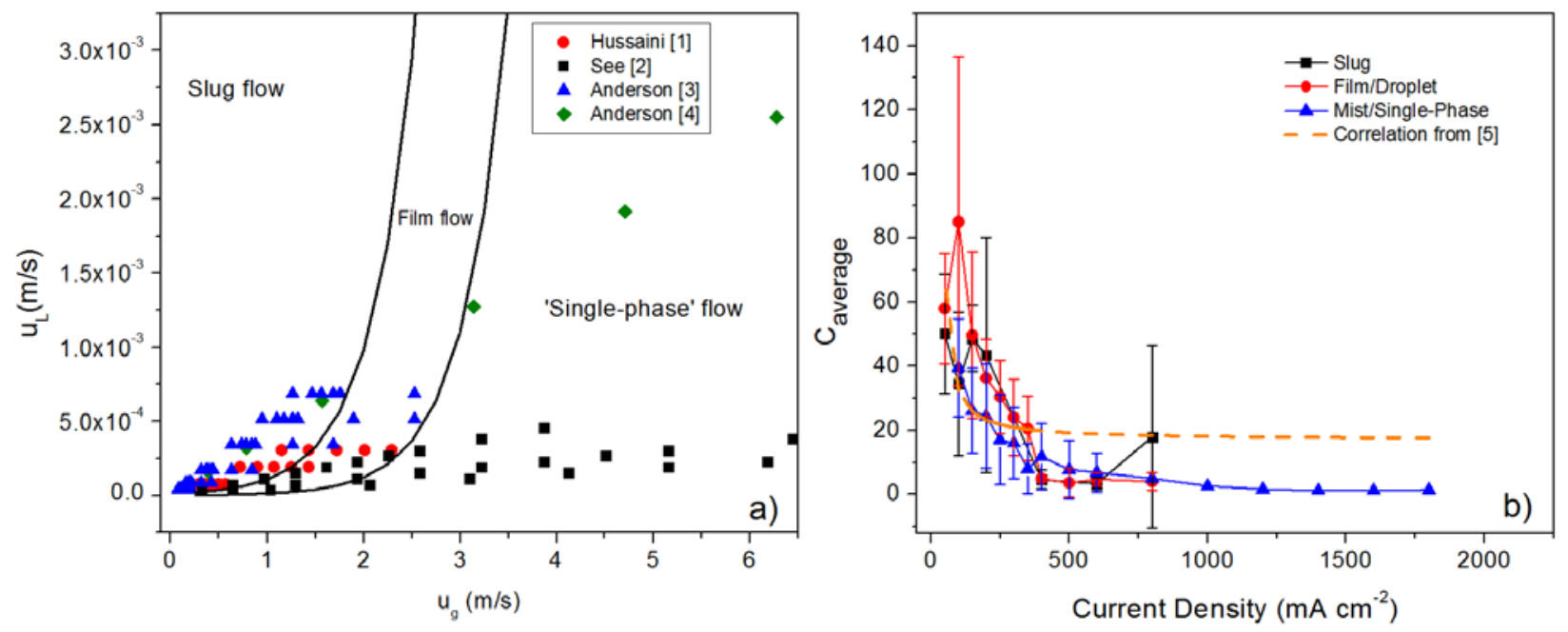

Fig. 5 a) All the data considered in this paper [1-4] in terms of the gas and liquid velocities. The flow regime domains (slug, film, 'single' phase) are defined by the correlation provided by Hussaini and Wang [1] b) The value of $C$ calculated for each flow regime and averaged at each current density. Also included is a previously derived correlation from [5].

From this map, $C$ can be defined for each flow regime: $C_{\text {slug }}, C_{\text {film/droplet }}, C_{\text {single-phase. }}$ For each regime, $C$ is analyzed as a function of the current density. Thus, data from multiple groups may be averaged in a given regime at a given current density. The data may also consider the same gas and liquid flow rates but with different materials (e.g. different GDLs studied at identical operating conditions). When the $C$ value is analyzed specific to each regime at each current 
density ( $C_{\text {average }}$ ), there is no clear difference between them as shown in Fig. 5b. The same behavior is noted for each regime where a higher value of $C$ is generally found at lower current densities $\left(<500 \mathrm{~mA} \mathrm{~cm}^{-2}\right)$. This result does not match expected behavior, as Kandilkar et al. [21] have shown the flow regime to be characterized by the two-phase flow multiplier. For instance, $C$ should remain reasonably low for the 'single' phase regime since here the influence of liquid water is supposed to be greatly diminished. It is also expected that slug flow would lead to a higher pressure drop than film flow (a higher two-phase flow multiplier and thus higher value of $C)$, but this is not the trend observed from active fuel cell data.

Also shown in Fig. 5b is a previously developed correlation [5]:

$$
C=C^{*}+Y \exp \left[\frac{Z}{i}\right]
$$

where $i$ is the current density $\left(\mathrm{mA} \mathrm{cm}^{-2}\right)$ and $Y$ and $Z$ are constants. This previous fit considered all of the data from [5] with $Y=12.1+/-3.2$ and $Z=82+/-17$ (error bars from a 95\% confidence interval). $C^{*}$ was fixed at 5 , considering that $C=5$ is for laminar flow regimes. It captures the overall trend in the data but still does not yield the quantitative comparison. Therefore, additional information is needed to calculate an accurate value of $C$ consistent with expected behavior of each flow regime.

Thus, this paper's novel contribution is a new flow regime specific to PEM fuel cells (the accumulating regime) that can further divide this data into regimes that lead to expected results of $C$ as a function of current density for each flow regime.

\section{UPDATED LM APPROACH: 'ACCUMULATING' FLOW REGIME IN PEM FUEL CELLS}

An additional regime is considered in the analysis to more accurately calculate $C$ in view of the high two-phase flow multipliers observed at low current densities. This regime is referred to as the 'accumulating' flow regime, which is an area where the slug residence time is so large that the liquid can be considered stagnant. Even with fixed $\chi^{2}$ at each current density, a minimum gas velocity must be reached to purge the cell and induce a 'two-phase' system closer to the one for which the original LM approach was intended. Lower current densities lead to more accumulation, which is not physically captured in the classical LM approach. Moreover, there exists no model to describe this trend in the literature. Long residence times were noted in an exsitu setup [44]. Also, the work of Dunbar et al. [18] showed that the plugs of liquid water in the 
channels (monitored by MRI in an active fuel cell) often move from surface defect to surface defect. Their $7 \mathrm{~cm}$ channel had gas flows of approximately $5.5 \mathrm{~cm} \mathrm{~s}^{-1}$ but a liquid slip velocity of $0.04 \mathrm{~cm} \mathrm{~s}^{-1}$. That leads to a slug residence time on the order of 175 seconds. Therefore, extended slug residence time resulted in the discovery of a stick and slip transport mode. Ex-situ results have also shown that gas flow through the GDL from one channel to another can cause a slug to stop moving [38]. The data from Hussaini and Wang [1] also reported a wetted area ratio, which described how much of a flow field channel was experiencing two-phase flow. The proposed accumulating flow regime is consistent with their proposed wetted area concept.

However, the analysis here cannot rely on direct observation of the flow regime in all cases since all pressure drop data was not clearly reported along with their specific flow regimes in the literature. Thus, the approach here is a qualitative logic scheme to narrow the area that may be the accumulating regime. The following were assumed throughout the analysis: 1) water is more likely to accumulate at low gas flow rates via less convective removal ability [39]; 2) water can also accumulate at low liquid flow rates due to smaller droplet sizes and thus smaller drag force for removal [40-42,]; 3) the proposed accumulating regime boundaries are broadly consistent with the visualization results of Anderson in a non-operating fuel cell [43]. In that work, the percentage change in pressure drop was a function of water accumulation in the channels depending on whether the flow rates were increased or decreased. Thus, it was also seen that higher percentage changes in the active fuel cell were indicative of more water accumulation [3,4]; and 4) the flow regime of Hussaini and Wang [1] is broadly applicable to different operating fuel cells.

From this framework, several initial boundaries were drawn for the accumulating flow regime. These results (not shown) were refined by examining where on the map certain minimum criteria for $C$ were met. Specific to the accumulating regime analysis, there is the problem of including data that has a low value of $C$ and the problem of excluding data with a high value of $C$. To address this issue, criteria were set for the accumulation regime from each of the four data sets based on five critical values of $C: 5,10,15,25$, and 50. From this, the best results occurred at $C=15$. Less than this value, and much of the flow regime map was considered 'accumulating'; much greater than 15 led to high multiplier values in the single-phase region, which is physically unrealistic. The symbol in each flow regime map in Fig. 6a is the particular group the data is from; a filled-in symbol means the criteria has been 'met' to consider 
the point as 'accumulating'. For any given group of data in Fig. 6b, the $x$ marker indicates a duplicate data point where $C>15$ and the + marks where there are duplicate data points for $C<$ 15. Duplicates on the flow regime map occur when running the same conditions but with a different GDL for instance. Thus, visualizing the data both ways is necessary to observe the full data set.
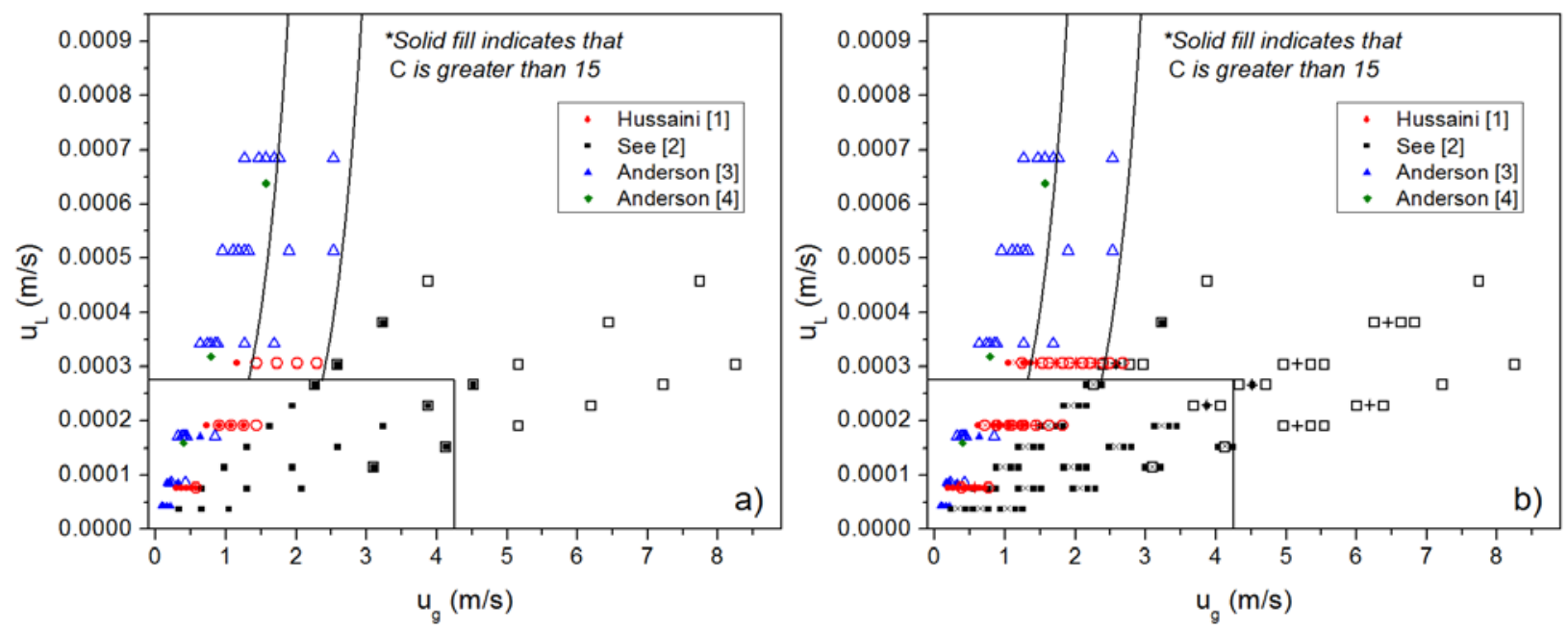

Fig. 6. a) Proposed boundary for the accumulating regime ( $u_{g}<4.25 \mathrm{~m} / \mathrm{s}$ and $u_{L}<2.75 \times 10^{-4} \mathrm{~m} / \mathrm{s}$ ). The solid fill indicates points where the value of $C$ is greater than 15. b) The same data and accumulating regime in (a) expect duplicate points are included. Duplicate points are offset with the center being an $x$ or + based on whether the criteria of $C=15$ is met or not.

In each case the accumulating regime location agreed with the results of Anderson, where accumulation was noted based on high values of hysteresis in the ascending and descending approaches [3,4] and direct visualization was afforded to the authors. Also consistent with this boundary for the accumulating regime, the boundary for the gas velocity is consistent with the results of Lu et al. [44], where the slug flow residence time increased from approximately 25 seconds at a gas velocity of $4 \mathrm{~m} / \mathrm{s}$ to approximately 225 seconds at a gas velocity of $0.5 \mathrm{~m} / \mathrm{s}$. These long residence times are akin to accumulated liquid water but not traditional slug flow [18].

The revised flow regime map for active fuel cells is shown in Fig. 7. The gas and liquid velocities are extended here to show all of the data from [1-4]. The boundaries between slug and film and film and 'single' phase are the same as those determined by Hussaini and Wang [1]. In 
general, the accumulating boundary is defined as: $\mathrm{u}_{\mathrm{g}}<4.25 \mathrm{~m} / \mathrm{s}$ and $\mathrm{u}_{\mathrm{L}}<2.75 \times 10^{-4} \mathrm{~m} / \mathrm{s}$. It should be noted that the flow regime map here relates specifically to the data collected in Table 1 , where the channel cross sectional area varied from $0.28-1.56 \mathrm{~mm}^{2}$. This range is relevant to typical PEM fuel cell operating conditions, and care should be taken before extending the results to different geometries.

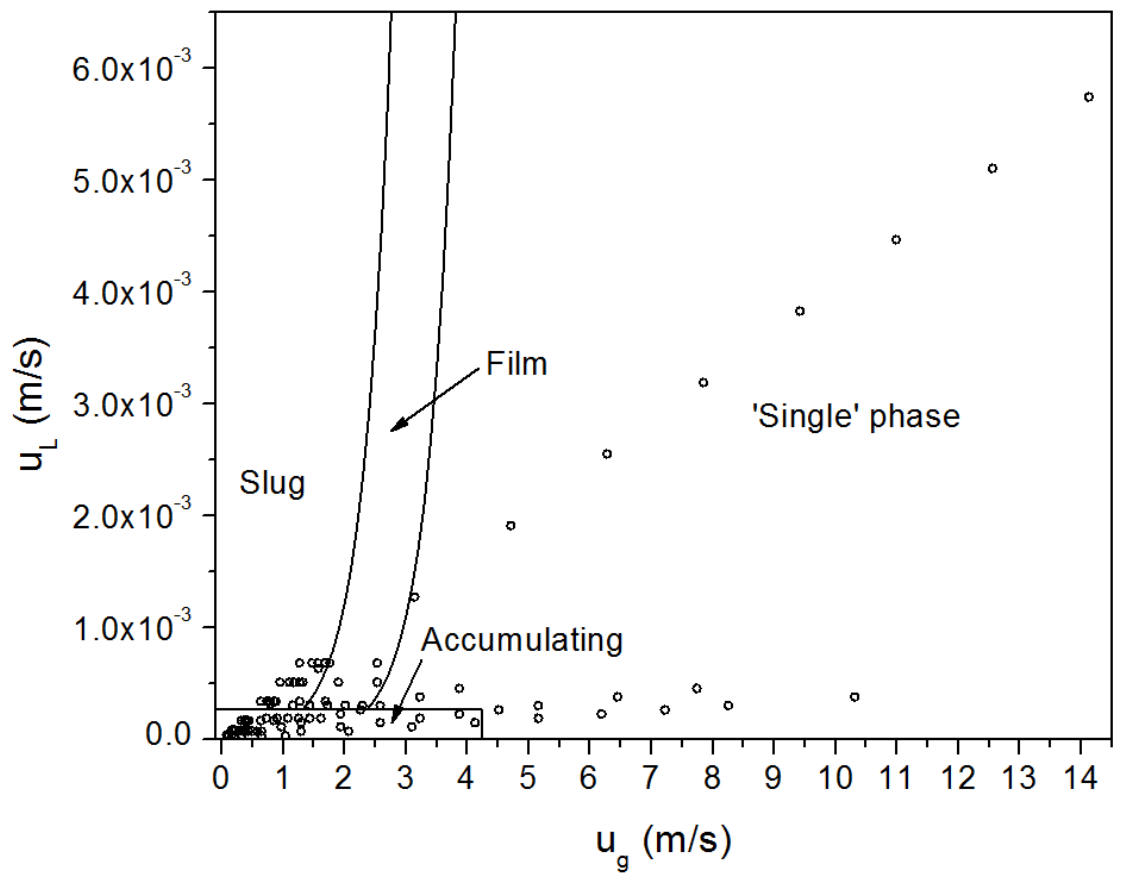

Fig. 7. Flow regime map proposed based on the analysis here, showing the regime boundaries between slug, film, accumulating, and 'single' phase

\subsection{C as a function of current density at each flow regime (accumulating, slug, droplet/film, and 'single' phase)}

Based on these results, $C$ can be determined as a function of current density for each of the four flow regimes from Fig. 7. The data was firstly sorted by flow regime. Then, the data was ordered based on the current density. Where multiple current densities are noted in the same regime, these values are averaged and a standard deviation is determined. The resulting average and standard deviation are the data presented in Fig. 8. 

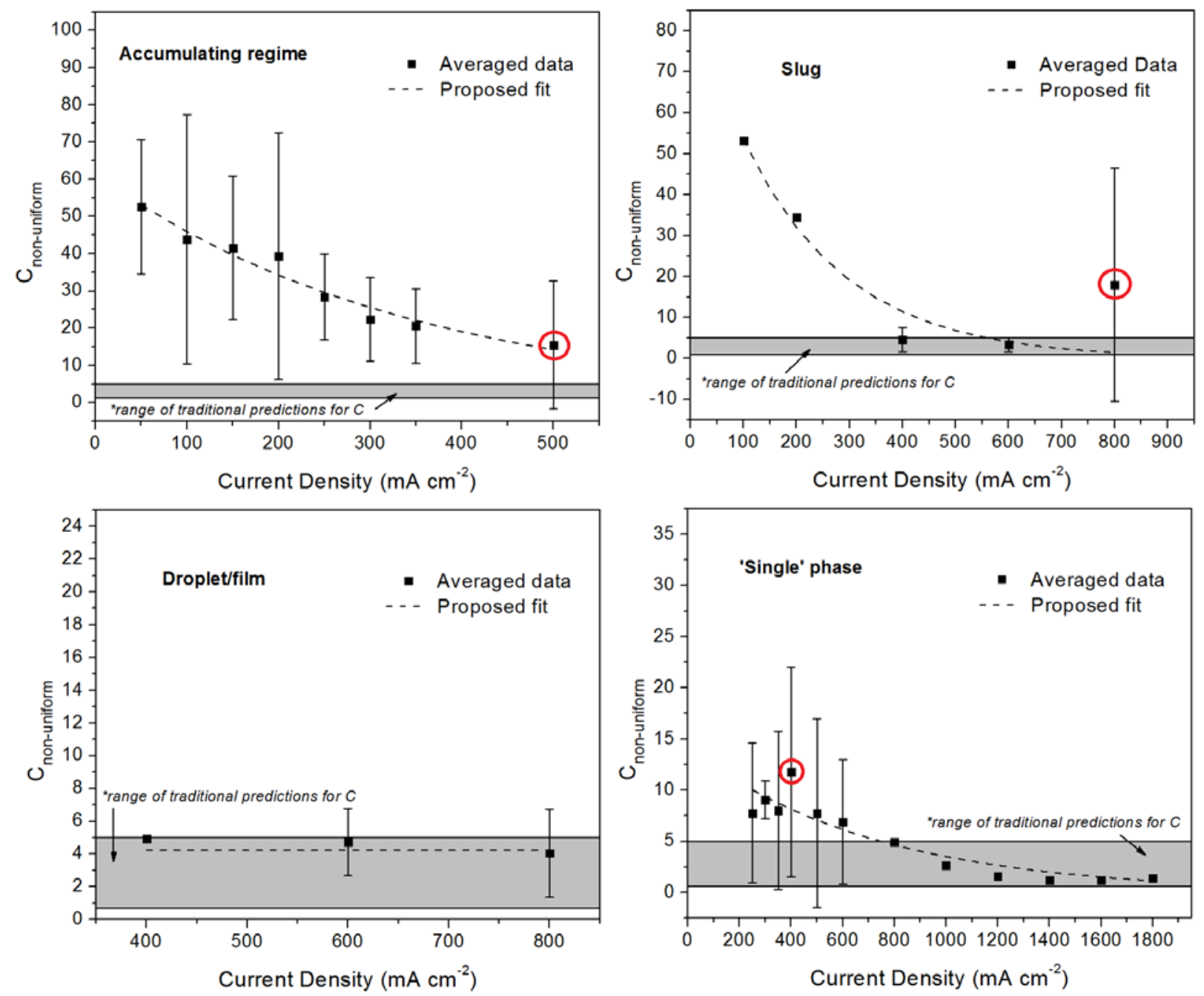

Fig. 8. The averaged value of the non-uniform $C$ value at each current density for each flow regime (accumulating, slug, film, 'single' phase). The dashed line is a proposed fit for $C$ as a function of current density for that flow regime. These expressions are listed in Table 4. The circled data represents values inconsistent with expectation and/or with substantially high standard deviations.

The expressions for $C$ for each regime are in Table 4. The fit was an exponential curve solved with a nonlinear least squares method using Matlab’s Trust-Region algorithm. The curves qualitatively match the data quite well. The lower $\mathrm{R}^{2}$ values can be attributed to a data point with a large standard deviation. The three circled data points in Fig. 8 are data points with high standard deviations (large spread in the data) and/or are opposite accepted trends. If the same regression analysis is done without these points, the trend lines remain nearly identical but the $\mathrm{R}^{2}$ value increases. For instance, the $\mathrm{R}^{2}$ for slug flow would increase to 0.976 and the $\mathrm{R}^{2}$ for the single phase flow would increase to 0.928 . 
Table 4. Proposed correlation for each flow regime with ranges in the coefficients based on a $95 \%$ confidence interval.

\begin{tabular}{|c|c|c|c|c|c|}
\hline Proposed Correlation & $\begin{array}{l}\text { Range of } i \\
\left(\mathrm{~mA} \mathrm{~cm}^{-2}\right)\end{array}$ & $\begin{array}{c}\text { A }(95 \% \\
\text { confidence) }\end{array}$ & B (95\% confidence) & $\mathbf{R}^{2}$ & Eq. \# \\
\hline$C_{a c c}=A \exp [B * i]$ & $50-500$ & $61.47+/-7.8$ & $-0.002929+/-0.000691$ & 0.959 & (11) \\
\hline$C_{\text {slug }}=A \exp [B * i]$ & $100-800$ & $\begin{array}{c}89.54+/- \\
99.76\end{array}$ & $-0.005148+/-0.0007161$ & 0.817 & (12) \\
\hline$C_{\text {film }}=4.2+1-2.4$ & $400-800$ & -- & -- & -- & (13) \\
\hline$C_{\text {single }}=A \exp [B * i]$ & $200-1800$ & $14.25+-/ 4.55$ & $-0.001399+/-0.00064$ & 0.846 & (14) \\
\hline
\end{tabular}

Considering the spread in the data (overall range of $C$ is 0 to 144 as shown in Fig. 3b) and reasonable agreement in trend line and data for each regime, the proposed fits for the regimes are considered acceptable.

\subsection{Discussion of the new LM approach}

Importantly, there is evidence for water accumulation in the literature [1,9,18], and this new flow regime map captures this behavior. Even accounting for evaporation in their calculation, Hussaini and Wang [1] note that with a dry gas $(\mathrm{RH}=26 \%)$ and higher current densities (800 $\mathrm{mA} \mathrm{cm}{ }^{-2}$ ), liquid water could still accumulate at lower gas flows. They attributed this to low gas flow rates being unable to remove water (such as occurs at low current densities and low gas stoichiometries), which is consistent with the results presented here. Along these lines, Dunbar et al. [18] pointed out that the two-phase flow literature generally only observes slug flow if the gas and liquid flow rates are similar. This does not occur in fuel cells as evidenced by the magnitudes of the velocities in the flow regime maps. However, their MRI results did show in general that water would accumulate and only be expelled after long times in the channels, which is not strictly slug flow as defined in conventional flow channels. This type of accumulation and eventual expulsion of water is further consistent with the long 'slug' residence times in [44]. Since slug flow has been observed by several other research groups [1-4,44,45] and long residence times have been noted in certain conditions, the accumulating regime proposed here attempts to capture these dynamics. 
Directly important to fuel cell operation, Bachman et al. [9] used neutron imaging to quantify accumulation in an active fuel cell at $500 \mathrm{~mA} \mathrm{~cm}^{-2}$, and showed higher accumulation led to lower voltage performance. Under the same operating conditions but changing the channel length of ten parallel channels, they were able to increase the superficial velocities due to an increase in the active area. The case with the highest accumulation (shortest channels; $5 \mathrm{~cm}$ long) had the lowest voltage and largest standard deviation in the voltage signal. At the condition with the least accumulation (longest channels; $25 \mathrm{~cm}$ long), the superficial gas and liquid velocities were 2.83 and $0.000254 \mathrm{~m} / \mathrm{s}$, respectively, just on the border between the accumulating and single-phase regime proposed here. Importantly, that reduction in accumulation in the gas flow channels led to a higher voltage and a more stable voltage signal (611 +/- $5 \mathrm{mV}$ vs. 539 +/- $128 \mathrm{mV})$ [9].

It is also worth drawing attention to the ex-situ results discussed before in terms of ex-situ flow regime maps, such as those in $[13,44,45]$. These results are not directly applicable to the active PEM fuel cells, as the transition between film and 'single' phase occurs at very high gas velocities. Fig. 9 shows the flow regime map proposed in [13] with the data and map from this paper.

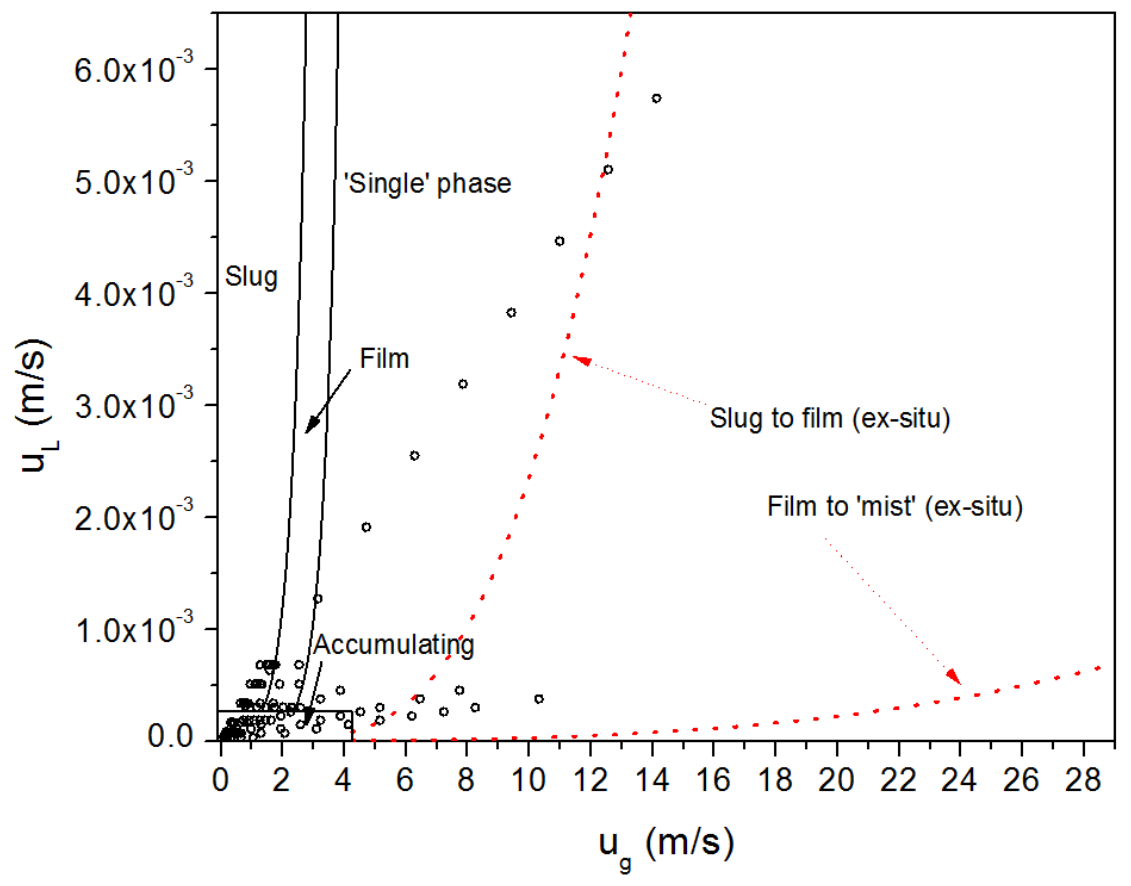

Fig. 9. Ex-situ flow regime maps based on the data of Grimm et al. [13] along with the proposed flow regime and experimental data considered in this work 
The work in $[44,45]$ has similarly high velocities for the transition from film flow to mist flow. If the map for active fuel cells (in-situ) here only contained one data set, it would be difficult to have confidence in the difference between the in-situ and ex-situ map. However, the data in Fig. 9 is from three groups and four different fuel cells. The ex-situ work has greatly advanced the approach of flow regimes in PEM fuel cells, and this work builds on that framework. Though the boundaries between regimes switch, the same general flow patterns exist in both the active and non-active (ex-situ) setups. Additional ex-situ work has recently showed the liquid water area coverage ratio increases exponentially at lower gas velocities [22], consistent with where the accumulating regime is noted in this work.

In each instance $\chi^{2}$ is calculated here, the water velocity is based on all product water existing in the liquid state and emerging into the cathode flow field channels. The analysis has not considered the conditions existing on the anode side or evaporation. The anode flow rate, flow field configuration (e.g. co-flow vs. counter-flow), GDL, MPL, temperature, pressure, and relative humidity will affect the overall water balance in an operating fuel cell [46,47]. These terms (among others) have an impact on the relative balance between back-diffusion, electroosmotic drag, hydraulic permeation, and thermoosmotic drag. There is no consensus in the fuel cell literature in how to analytically account for all of these terms (without extensive assumptions), though generally most of the water tends toward the cathode. For instance, the net water transport coefficient ( $\alpha$; the ratio of water flux to the proton flux) used to calculate all of the liquid velocities in the flow pattern map in Fig. $1 \mathrm{~d}$ was set to 0.1 for all of their conditions for convenience. This convenience stems from the aforementioned factors that are hard to quantitatively account for (and that is with data from one group) even though the operating conditions were varied. Additionally, Médici and Allen [48] discussed how pore network simulations applied to PEM fuel cell materials have not been able to incorporate evaporation. The model they subsequently developed addressed this for random porous media, though the results depended on the randomized pore arrangement in addition to the temperature and relative humidity. Furthermore, it was assumed the volumetric flow rate was uniform at the catalyst layer. This is inconsistent with the approach developed by Zhang et al. [33] and utilized here that showed more water breaks through at the exit where the pressure drop across the cathode GDL is minimal. Hussaini and Wang [1] showed more accumulation at the exit experimentally, and also incorporated a local liquid velocity model where the velocity was increased linearly from inlet to 
outlet. Thus, the assumption of product water entering the cathode is reasonable, though clearly there is potential for improvement.

Another issue is that both [1] and [21] show regime changes down the length of the channel are possible. This is also consistent with observations from the author (Anderson) and has been numerically studied by Fontana et al. [26]. The LM approach as modified here allows for one to use the superficial velocity based on the water volumetric flow rate and the cross sectional area via the integration of the liquid water velocity profile as done in Eq. 4. This equation may be examined in the future to see if the local calculation of the velocities (e.g. two-phase pressure drop in the first third of the channel vs. the last third of the channel) could lead to a different prediction of the flow regime.

\subsection{Application to operating PEM fuel cells}

In PEM fuel cells, low values of $\chi^{2}$ occur at high gas velocities relative to the liquid velocity (Eq. 3). Such a system would be one with a high gas stoichiometry. Considering the range of two-phase flow multipliers considered in this analysis [1-4], a designer of fuel cell flow field channels should be aware of the general accuracy of these predictions in each regime. The range of $\chi^{2}$ here covers the range shown in Fig. 2 and thus covers all of the data from the four sets. This analysis assumes a 50\% error in $C$ for each flow regime from Eqs. 11-14. These results are in Fig. 10. In both cases of $\chi^{2}$ presented here and for the accumulating, slug, and single phase regimes, the magnitude of the error bar increases with lower current density. For low values of $\chi^{2}$ $\left(\chi^{2}=0.001\right)$, a $50 \%$ error in $C$ does not lead to greatly different two-phase flow multiplier

predictions. However, in systems with high values of $\chi^{2}$ the results are much more sensitive to error in $C$. At low current densities $\left(<600 \mathrm{~mA} \mathrm{~cm}^{-2}\right)$ and the higher end of $\chi^{2}\left(\chi^{2}=0.03\right)$, a $50 \%$ error in the prediction of $C$ leads to an error in the prediction of the two-phase flow multiplier greater than $50 \%$. Thus, a designer will want to minimize $\chi^{2}$ as it will lead to a more accurate prediction and a lower magnitude of the two-phase pressure drop. 

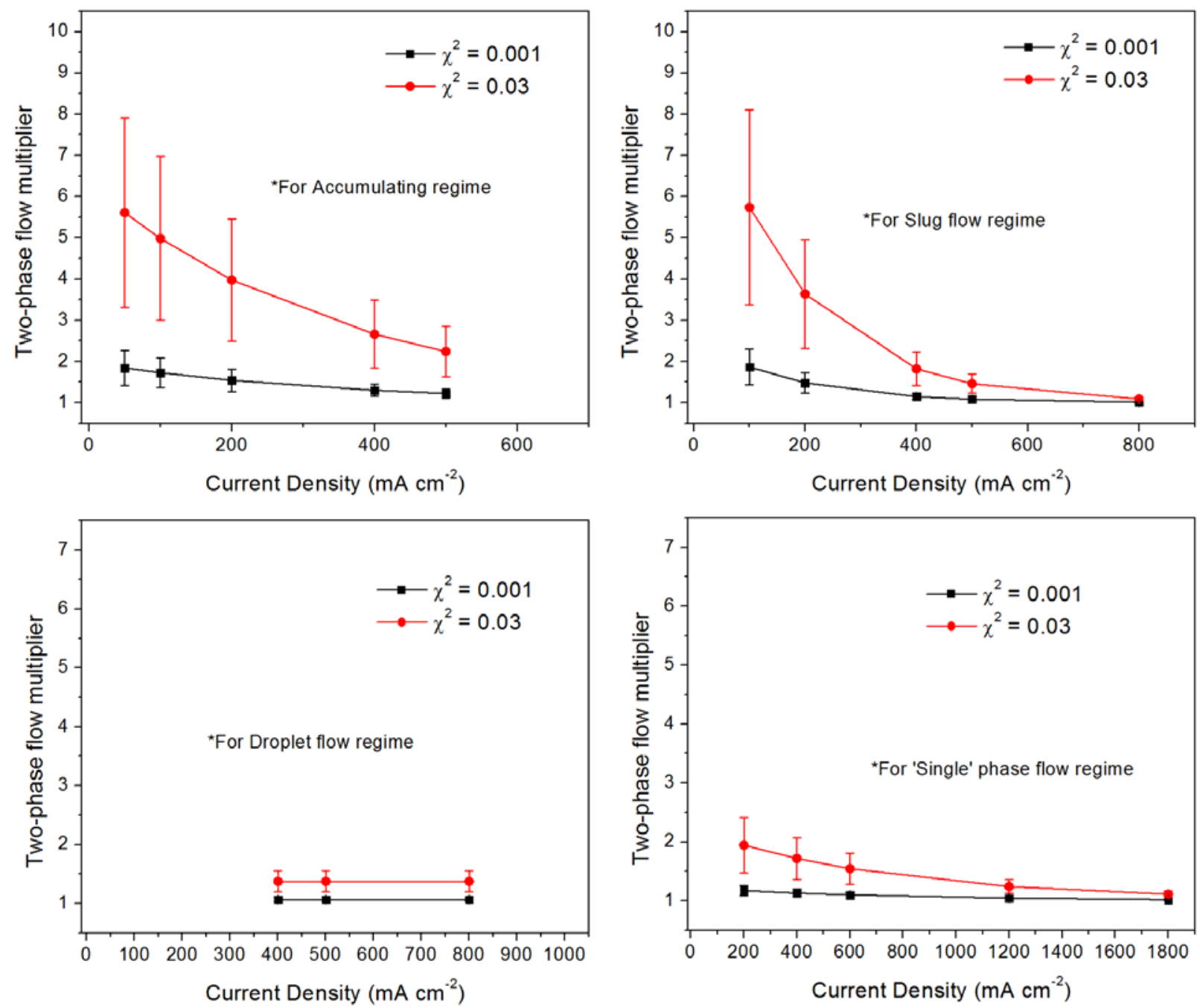

Fig. 10. Two-phase flow multiplier calculation for each flow regime (accumulating, slug, droplet, and 'single' phase) based on the proposed correlations of $C$ at $\chi^{2}=0.001$ and $\chi^{2}=0.03$. The error bars are based on $+/-50 \%$ in the calculated value of $C$.

Considering all of the analysis, the following decision tree in Fig. 11 is an illustration of how this information can be utilized by a designer of a fuel cell flow channel. This figure highlights the broader applicability of the method, so further calculations of pressure drop at a specific condition are not provided. Initially, a channel design can be considered based on the requirements of the fuel cell (such as could be done by only considering a single-phase system). Typical operating conditions can also be specified. This allows for the calculation of $\chi^{2}$ based on the liquid and gas velocities (determined from Faraday’s law, the gas stoichiometry, temperature, pressure, and the channel cross-section) and the liquid and gas viscosities (determined at a given 
temperature and relative humidity). The calculated velocities can also be compared to the flow regime map in Fig. 7. Based on the regime, $C$ can be calculated accordingly to Eqs. 11-14 in Table 4.

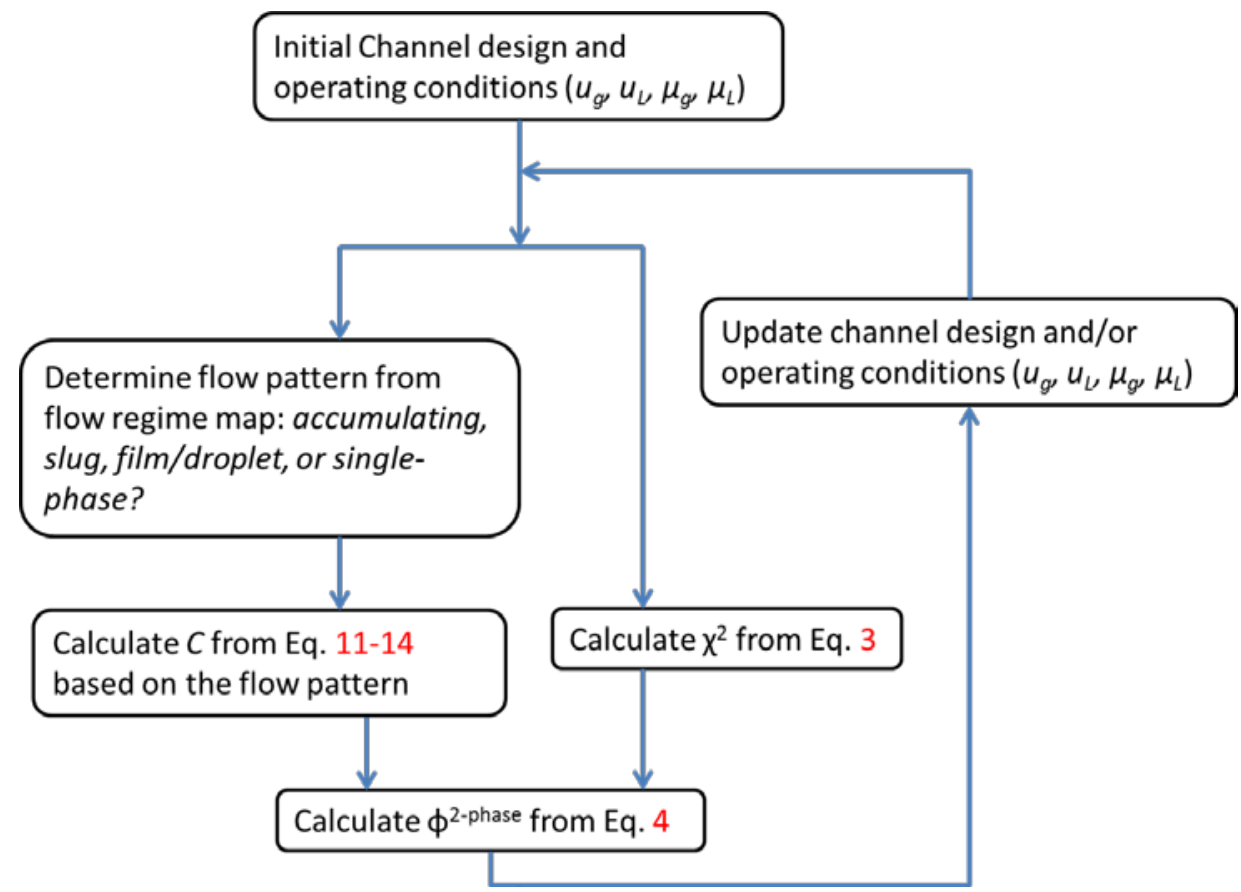

Fig. 11. A decision matrix showing the logic of this modified LM method to fuel cell designers. These parameters consider channel design and operating conditions.

This process can be done at each anticipated current density as the gas and liquid velocities change with current density and gas stoichiometry. Based on these results, the two-phase flow multiplier can be predicted and thereby the two-phase pressure drop. If the two-phase pressure drop is unacceptably high, indicating high parasitic power loss (the designer can set a definition of too high), the designer can manipulate the design or operating conditions to lower the anticipated two-phase pressure drop. If further CFD-based designs are required, these results are a much stronger starting point in the design to save computational costs.

\section{CONCLUSIONS}

This paper examined the application of the Lockhart-Martinelli approach to two-phase flow pressure data collected in operating PEM fuel cells from four different data sets in the literature [1-4]. A non-uniform water injection scheme for better applicability to PEM fuel cells was used in an updated LM approach, allowing for a determination of the Chisholm parameter $C$ at each 
data point. Importantly, these data sets considered different operating conditions, materials, and geometries of PEMFCs, so a full range of $C$ values was noted. Major conclusions include:

1. Traditional predictions for $C$ are incapable of predicting the two-phase flow multipliers in active PEM fuel cells, particularly at current densities $<500 \mathrm{~mA} \mathrm{~cm}^{-2}$.

2. An accumulating flow regime is proposed for water droplets or slugs with especially long residence times, as is typical at low current densities $\left(<500 \mathrm{~mA} \mathrm{~cm}^{-2}\right)$ and thus low air flow rates. This regime is added to the map of Hussaini and Wang [1] to capture the water accumulation at low air flow rates The boundaries for the accumulating regime are $\mathrm{u}_{\mathrm{g}}<4.25 \mathrm{~m} / \mathrm{s}$ and $\mathrm{u}_{\mathrm{L}}<2.75 \times 10^{-4} \mathrm{~m} / \mathrm{s}$.

3. Expressions are derived for how $C$ varies with current density in each flow regime: $C_{\text {Accumulating, }} C_{\text {slug }}, C_{\text {film/droplet }}, C_{\text {single-phase }}$. While there is variability in these data sets, they represent a much more accurate representation of the flow regimes occurring in PEM fuel cells and lead to more reasonable predictions for $C$ and two-phase pressure drop in each flow regime.

\section{ACKNOWLEDGMENTS}

The authors would like to acknowledge Dr. Xiaotao Bi and Dr. David P. Wilkinson at the University of British Columbia. Our gratitude is also extended to Dr. Mauricio Blanco for his work and discussions with the authors on the serpentine flow field channel fuel cell. 


\section{REFERENCES}

[1] Hussaini, I. S., \& Wang, C. Y. (2009). Visualization and quantification of cathode channel flooding in PEM fuel cells. Journal of Power Sources, 187(2), 444-451.

[2] See, E. (2013). In situ measurement, characterization, and modeling of two-phase pressure drop incorporating local water saturation in PEMFC gas channels. M.S. thesis, Rochester Institute of Technology, Troy, NY.

[3] Anderson, R., Wilkinson, D. P., Bi, X., \& Zhang, L. (2011). Two-phase flow pressure drop hysteresis in an operating proton exchange membrane fuel cell. Journal of Power Sources, 196(19), 8031-8040.

[4] Anderson, R. (2012). Characterization of gas-liquid two-phase flow in a proton exchange membrane fuel cell. Ph.D. thesis, University of British Columbia, Vancouver, BC.

[5] Anderson, R., Zhang, L., Wilkinson, D.P. (2014). An analysis of two-phase flow pressure drop in operating proton exchange membrane fuel cell channels with the Lockhart-Martinelli approach. 12th International Conference on Nanochannels, Microchannels, and Minichannels, FEDSM2014-21288.

[6] Trabold, T. A. (2005). Minichannels in polymer electrolyte membrane fuel cells. Heat Transfer Engineering, 26(3), 3-12.

[7] Li, H., Tang, Y., Wang, Z., Shi, Z., Wu, S., Song, D., ... \& Mazza, A. (2008). A review of water flooding issues in the proton exchange membrane fuel cell. Journal of Power Sources, 178(1), 103-117.

[8] Dai, W., Wang, H., Yuan, X. Z., Martin, J. J., Yang, D., Qiao, J., \& Ma, J. (2009). A review on water balance in the membrane electrode assembly of proton exchange membrane fuel cells. International Journal of Hydrogen Energy, 34(23), 9461-9478.

[9] Bachman, J., Charvet, M., Santamaria, A., Tang, H. Y., Park, J. W., \& Walker, R. (2012). Experimental investigation of the effect of channel length on performance and water accumulation in a PEMFC parallel flow field. International Journal of Hydrogen Energy, 37(22), 17172-17179.

[10] Burkholder, M. B., Siefert, N., \& Litster, S. (2014). Nonlinear analysis of voltage dynamics in a polymer electrolyte fuel cell due to two-phase channel flow. Journal of Power Sources. 267, 243-254.

[11] Liu, X., Guo, H., Ye, F., \& Ma, C. F. (2007). Water flooding and pressure drop characteristics in flow channels of proton exchange membrane fuel cells. Electrochimica Acta, 52(11), 3607-3614. 
[12] Barbir, F., Gorgun, H., \& Wang, X. (2005). Relationship between pressure drop and cell resistance as a diagnostic tool for PEM fuel cells. Journal of Power Sources, 141(1), 96-101.

[13] Grimm, M., See, E. J., \& Kandlikar, S. G. (2012). Modeling gas flow in PEMFC channels: Part I-Flow pattern transitions and pressure drop in a simulated ex situ channel with uniform water injection through the GDL. International Journal of Hydrogen Energy, 37(17), 1248912503.

[14] Barbir, F. (2005). "PEM Fuel Cells: Theory and Practice," Elsevier Academic Press, Burlington, MA.

[15] Blanco, M. (2011). Study of selected water management strategies for proton exchange membrane fuel cells. Ph.D. thesis, University of British Columbia, Vancouver, BC.

[16] Anderson, R., Zhang, L., Ding, Y., Blanco, M., Bi, X., \& Wilkinson, D. P. (2010). A critical review of two-phase flow in gas flow channels of proton exchange membrane fuel cells. Journal of Power Sources, 195(15), 4531-4553.

[17] Bazylak, A. (2009). Liquid water visualization in PEM fuel cells: a review. International Journal of Hydrogen Energy, 34(9), 3845-3857.

[18] Dunbar, Z. W., \& Masel, R. I. (2008). Magnetic resonance imaging investigation of water accumulation and transport in graphite flow fields in a polymer electrolyte membrane fuel cell: Do defects control transport?. Journal of Power Sources, 182(1), 76-82.

[19] Lee, J., Hinebaugh, J., \& Bazylak, A. (2013). Synchrotron X-ray radiographic investigations of liquid water transport behavior in a PEMFC with MPL-coated GDLs. Journal of Power Sources, 227, 123-130.

[20] Kim, S. G., \& Lee, S. J. (2013). A review on experimental evaluation of water management in a polymer electrolyte fuel cell using X-ray imaging technique. Journal of Power Sources, 230, 101-108.

[21] Kandlikar, S. G., See, E. J., Koz, M., Gopalan, P., \& Banerjee, R. (2014). Two-phase flow in GDL and reactant channels of a proton exchange membrane fuel cell. International Journal of Hydrogen Energy, 39(12), 6620-6636.

[22] Banerjee, R., \& Kandlikar, S. G. (2014). Liquid water quantification in the cathode side gas channels of a proton exchange membrane fuel cell through two-phase flow visualization. Journal of Power Sources, 247, 9-19.

[23] Wang, Y., Basu, S., \& Wang, C. Y. (2008). Modeling two-phase flow in PEM fuel cell channels. Journal of Power Sources, 179(2), 603-617. 
[24] Bıyıkoğlu, A. (2005). Review of proton exchange membrane fuel cell models. International Journal of Hydrogen Energy, 30(11), 1181-1212.

[25] He, G., Ming, P., Zhao, Z., Abudula, A., \& Xiao, Y. (2007). A two-fluid model for two-phase flow in PEMFCs. Journal of Power Sources, 163(2), 864-873.

[26] Fontana, É., Mancusi, E., Ulson de Souza, A. A., \& Guelli Ulson de Souza, S. (2013). Flow regimes for liquid water transport in a tapered flow channel of proton exchange membrane fuel cells (PEMFCs). Journal of Power Sources, 234, 260-271.

[27] Jiang, F., \& Wang, C. Y. (2014). Numerical modeling of liquid water motion in a polymer electrolyte fuel cell. International Journal of Hydrogen Energy, 39(2), 942-950.

[28] Carton, J. G., Lawlor, V., Olabi, A. G., Hochenauer, C., \& Zauner, G. (2012). Water droplet accumulation and motion in PEM (Proton Exchange Membrane) fuel cell mini-channels. Energy, 39(1), 63-73.

[29] Herescu, A., \& Allen, J. S. (2012). The influence of channel wettability and geometry on water plug formation and drop location in a proton exchange membrane fuel cell flow field. Journal of Power Sources, 216, 337-344.

[30] Talimi, V., Muzychka, Y. S., \& Kocabiyik, S. (2012). A review on numerical studies of slug flow hydrodynamics and heat transfer in microtubes and microchannels. International Journal of Multiphase Flow, 39, 88-104.

[31] Lockhart, R. W., \& Martinelli, R. C. (1949). Proposed correlation of data for isothermal two-phase, two-component flow in pipes. Chem. Eng. Prog, 45(1), 39-48.

[32] Chisholm, D. (1967). A theoretical basis for the Lockhart-Martinelli correlation for twophase flow. International Journal of Heat and Mass Transfer, 10(12), 1767-1778.

[33] Zhang, L., Bi, X. T., Wilkinson, D. P., Anderson, R., Stumper, J., \& Wang, H. (2011). Gasliquid two-phase flow behavior in minichannels bounded with a permeable wall. Chemical Engineering Science, 66(14), 3377-3385.

[34] Morvay, Z., Gvozdenac, D. (2008). “Applied Industrial Energy and Environmental Management, Part III: Fundamentals for analysis and calculation of energy and environmental performance,” Wiley-IEEE Press.

[35] NIST Thermophysical Properties of Fluid Systems, http://webbook.nist.gov/chemistry/fluid/

[36] Lee, C. Y., \& Lee, S. Y. (2008). Pressure drop of two-phase plug flow in round minichannels: influence of surface wettability. Experimental Thermal and Fluid Science, 32(8), 17161722. 
[37] English, N. J., \& Kandlikar, S. G. (2006). An experimental investigation into the effect of surfactants on air-water two-phase flow in minichannels. Heat Transfer Engineering, 27(4), 99109.

[38] Hellstern, T., Gauthier, E., Cheah, M. J., \& Benziger, J. B. (2013). The role of the gas diffusion layer on slug formation in gas flow channels of fuel cells. International Journal of Hydrogen Energy, 38(35), 15414-15427.

[39] Cho, S. C., Wang, Y., \& Chen, K. S. (2012). Droplet dynamics in a polymer electrolyte fuel cell gas flow channel: Forces, deformation, and detachment. I: Theoretical and numerical analyses. Journal of Power Sources, 206, 119-128.

[40] Kimball, E., Whitaker, T., Kevrekidis, Y. G., \& Benziger, J. B. (2008). Drops, slugs, and flooding in polymer electrolyte membrane fuel cells. AIChE Journal, 54(5), 1313-1332..

[41] Kumbur, E. C., Sharp, K. V., \& Mench, M. M. (2006). Liquid droplet behavior and instability in a polymer electrolyte fuel cell flow channel. Journal of Power Sources, 161(1), 333-345.

[42] Lee, S. K., \& Ito, K. (2014). Cross-sectional visualization and analysis of droplet behavior in gas flow channel in PEFC. Journal of The Electrochemical Society, 161(1), F58-F66.

[43] Anderson, R., Wilkinson, D., Bi, X., \& Zhang, L. (2010). Two-phase flow pressure drop hysteresis under typical operating conditions for a proton exchange membrane fuel cell. ECS Transactions, 28(30), 127-137.

[44] Lu, Z., Kandlikar, S. G., Rath, C., Grimm, M., Domigan, W., White, A. D. \& Trabold, T. A. (2009). Water management studies in PEM fuel cells, Part II: Ex situ investigation of flow maldistribution, pressure drop and two-phase flow pattern in gas channels. International Journal of Hydrogen Energy, 34(8), 3445-3456.

[45] Lu, Z., Daino, M. M., Rath, C., \& Kandlikar, S. G. (2010). Water management studies in PEM fuel cells, part III: dynamic breakthrough and intermittent drainage characteristics from GDLs with and without MPLs. International Journal of Hydrogen Energy, 35(9), 4222-4233.

[46] Voss, H. H., Wilkinson, D. P., Pickup, P. G., Johnson, M. C., \& Basura, V. (1995). Anode water removal: a water management and diagnostic technique for solid polymer fuel cells. Electrochimica Acta, 40(3), 321-328.

[47] Anderson, R., Blanco, M., Bi, X., \& Wilkinson, D. P. (2012). Anode water removal and cathode gas diffusion layer flooding in a proton exchange membrane fuel cell. International Journal of Hydrogen Energy, 37(21), 16093-16103. 
[48] Médici, E. F., \& Allen, J. S. (2013). Evaporation, two phase flow, and thermal transport in porous media with application to low-temperature fuel cells. International Journal of Heat and Mass Transfer, 65, 779-788. 